This is a version of the accepted manuscript, which is made available for scholarly purposes only, in accordance with the journal's author permissions. The full citation is:

Roberts, K. P., Heaven, S., \& Banks, C. J. (2016). Comparative testing of energy yields from microalgal biomass cultures processed via anaerobic digestion. Renewable Energy, 87, 744-753.

http://www.sciencedirect.com/science/article/pii/S0960148115304286 doi:10.1016/j.renene.2015.11.009

\title{
Comparative testing of energy yields from micro-algal biomass cultures processed via anaerobic digestion
}

Keiron P. Roberts, Sonia Heaven, Charles J. Banks

Faculty of Engineering and the Environment, University of Southampton, Southampton, SO17 1BJ, UK

(Email K.P.Roberts@soton.ac.uk,S.Heaven@soton.ac.uk, C.J.Banks@soton.ac.uk)

\begin{abstract}
Although digestion of micro-algal biomass was first suggested in the 1950s, there is still only limited information available for assessment of its potential. The research examined six laboratory-grown marine and freshwater micro-algae and two samples from large-scale cultivation systems. Biomass composition was characterised to allow prediction of potentially available energy using the Buswell equation, with calorific values as a benchmark for energy recovery. Biochemical methane potential tests were analysed using a pseudo-parallel first order model to estimate kinetic coefficients and proportions of readily-biodegradable carbon. Chemical composition was used to assess potential interferences from nitrogen and sulphur components. Volatile solids (VS) conversion to methane showed a broad range, from 0.161$0.435 \mathrm{~L} \mathrm{CH}_{4} \mathrm{~g}^{-1} \mathrm{VS}$; while conversion of calorific value ranged from 26.4-79.2\%. Methane productivity of laboratory-grown species was estimated from growth rate, measured by changes in optical density in batch culture, and biomass yield based on an assumed harvested solids content. Volumetric productivity was 0.04-0.08 $\mathrm{L} \mathrm{CH}_{4} \mathrm{~L}^{-1}$ culture day ${ }^{-1}$, the highest from the marine species Thalassiosira pseudonana. Estimated methane productivity of the large-scale raceway was lower at $0.01 \mathrm{~L} \mathrm{CH}_{4} \mathrm{~L}^{-1}$ day $^{-1}$. The approach used offers a means of screening for methane productivity per unit of cultivation under standard conditions.
\end{abstract}

\section{Keywords}

Micro-algae, anaerobic digestion, biochemical methane potential, biodegradability kinetics, biomass yield, growth rate.

\section{$1 \quad$ Introduction}

Much of the recent focus on micro-algae as a potential source of biofuel has been through the extraction of bio-oil for subsequent trans-esterification [1]. Other research approaches have considered the production of hydrogen through biophotolysis [2, 3] and, more recently, by indirect photolysis and dark fermentation [4]. The potential for direct ethanol production 
appears limited, although the fermentation of starch storage products may be more favourable [5]. Research on anaerobic digestion of micro-algal biomass goes back more than 50 years [6] and the subject has been revisited a number of times since then [7-13]. More recently digestion has been considered as a means of improving the overall energy balance of biodiesel production [14-16]; as a substrate for co-digestion to improve volumetric biogas yields in digestion of less favourable substrates [17, 18], or with other carbon-rich wastes [19]; or as an adjunct to wastewater treatment [20, 21].

There are at least 30,000 known species of micro-algae, and one of the key research tasks for commercialisation for energy production purposes has been to screen for favourable composition and for ease of cultivation and processing. The main focus of this screening has been on lipid productivity [22], with less attention given to potential as a fermentation substrate. Micro-algal biomass could be used as the sole substrate in an anaerobic digestion process, and techno-economic and life cycle assessments for this appear favourable [23, 24]. In practice, however, serious issues may be encountered in long-term continuous digestion processes. Micro-algae from marine environments are likely to cause difficulties associated not only with high salinity but also with high sulphate concentrations [4, 25]. To date most micro-algae that have been tested for digestion have low carbon/nitrogen ratios that may contribute to high digester ammonia concentrations and toxicity [26]. Many micro-algal species have also shown low biodegradability, possibly due to the nature of the cell walls [27], although pre-treatments can improve methane yield [28]. When considering the potential for micro-algal digestion, it is therefore important that the origin and type of the micro-algal material is taken into consideration.

For micro-algae as a substrate for energy production it is also necessary to consider the overall energy balance associated with the production process. Although many factors contribute towards this, the overall biomass yield is a prime consideration as this determines the culture requirements in terms of reactor volume, mixing and harvesting energy per unit of production [29]. The current paper reports the specific methane yield of some common freshwater and marine micro-algal species in biochemical methane potential tests. These values are compared to the theoretical methane potential based on chemical composition and to the higher heat value measured by bomb calorimetry. The energy potential is then calculated based on the specific methane yield coupled with the growth rate and biomass productivity of each of the species considered. The approach thus provides a methodology for the initial screening of micro-algae before full kinetic evaluation of methane production and determination of any secondary limiting factors in semi-continuous digestion.

\section{$2 \quad$ Materials and methods}

\subsection{Micro-algal biomass}

The marine species Isochrysis galbana, Thalassiosira pseudonana, Nannochloropsis occulata, and Dunaliella sp. were obtained from the culture collection of the National Oceanographic Centre (Southampton, UK) and the freshwater Chlorella vulgaris and Scenedesmus spp. from the Culture Collection of Algae and Protozoa (CCAP, www.ccap.ac.uk). These micro-algae were cultured on Jaworski's Medium (JM) with the following components $\left(\mathrm{mg} \mathrm{L}^{-1}\right)$ : macro-nutrients and buffers $\mathrm{Ca}\left(\mathrm{NO}_{3}\right)_{2} .4 \mathrm{H}_{2} \mathrm{O} 20.00, \mathrm{KH}_{2} \mathrm{PO}_{4}$ 12.40, $\mathrm{MgSO}_{4} .7 \mathrm{H}_{2} 50.00, \mathrm{NaHCO}_{3} 15.90, \mathrm{H}_{3} \mathrm{BO}_{3} 2.48, \mathrm{MnCl}_{2} .4 \mathrm{H}_{2} 1.39,\left(\mathrm{NH}_{4}\right) 6 \mathrm{Mo}_{7} \mathrm{O}_{24} .4 \mathrm{H}_{2}$ 1.00, $\mathrm{NaNO}_{3}$ 80.00, $\mathrm{Na}_{2} \mathrm{HPO}_{4} .12 \mathrm{H}_{2} \mathrm{O} 36.00$; chelating agents EDTAFeNa 2.25, EDTANa 
2.25; vitamin supplements Cyanocobalamin 0.04, Thiamine $\mathrm{HCl} 0.04$, Biotin 0.04. The JM was made up with deionized water when used with freshwater species, and with artificial seawater (Ultramarine Synthetica sea salts, Bristol UK) for marine species. For biomass production each species was grown over a period of 10 days in a 20-litre glass culture vessel supplied with $10 \mathrm{~L} \mathrm{~min}^{-1}$ of air filtered through a $2 \mu \mathrm{m}$ glass fibre filter (Whatman $\mathrm{GF} / \mathrm{F}$ ). The cultures were maintained under constant illumination of $120 \mu \mathrm{mol} \mathrm{m} \mathrm{m}^{-2}$. Cultures were harvested using a continuous centrifuge (Powerfuge Pilot CARR Centritech) operating at $17000 \mathrm{~g}$ and at a flow rate of $1 \mathrm{~L} \mathrm{~min}^{-1}$. The harvested micro-algal centrifugate was then frozen at $-17^{\circ} \mathrm{C}$ until used.

Two samples of micro-algal material from large-scale bioreactors were also used. One was a culture of Scenedesmus grown in a 3000-litre tubular photobioreactor (PBR), and the other a mixed culture primarily consisting of Scenedesmus and Chlorella spp. taken from a $100 \mathrm{~m}^{2}$ raceway operating at a depth of $0.1 \mathrm{~m}$ : both reactors were located in Almeria, Spain [30]. Both cultures were grown using commercial fertiliser products and were harvested using a disc stack centrifuge (Alfa Laval Clara 15, LAPX 404 SGP-31G/TGP-61G). The Scenedesmus culture from the PBR was freeze-dried before shipping and use, whereas the raceway culture was frozen after harvesting and defrosted before use.

\subsection{Determination of micro-algal growth rate and yield}

The growth rate for each of the laboratory-grown micro-algal species was determined in 100 $\mathrm{ml}$ working volume Erlenmeyer flasks. Each flask had an optical glass side-arm tube of 10 $\mathrm{mm}$ path length, allowing direct readings of the culture optical density (OD) at $\lambda=678 \mathrm{~nm}$ to be taken using a spectrophotometer (Cecil 3000 series, Cecil Instruments, UK), without opening the flasks. The OD had been previously correlated with total suspended solids (TSS) for each species (results not reported here). The growth rate $\mu\left(\right.$ day $\left.^{-1}\right)$ on a volatile solids (VS) basis was calculated from equation 1.

$\mu=\frac{\operatorname{Ln}\left(\left(T S S_{t} \times V S \%\right) /\left(T S S_{0} \times V S \%\right)\right)}{\mathrm{t}-t_{0}}$

Where $\mathrm{TSS}_{0}$ and $\mathrm{TSS}_{\mathrm{t}}$ are the TSS concentrations based on OD at the start and end of the exponential growth phase, VS\% is the percentage VS content of the total solids (TS), and $t$ and $t_{0}$ are the start and end times in days.

Potential biomass yield in $\mathrm{g} \mathrm{VS} \mathrm{L} \mathrm{L}^{-1} \mathrm{day}^{-1}$ was calculated from the growth rate assuming a harvested solids concentration of $0.5 \mathrm{~g} \mathrm{VS} \mathrm{L}^{-1}$ and 12 hours of daylight-driven growth per day.

\subsection{Characterisation of micro-algal biomass}

Total suspended solids (TSS) and total and volatile solids (TS and VS) were measured using Standard Methods $2540 \mathrm{D}$ and G, respectively [31]. Total Kjeldahl N was determined using a Kjeltech block digestion and steam distillation unit according to the manufacturer's instructions (Foss Ltd, Warrington, UK). Elemental composition was determined using a FlashEA 1112 Elemental Analyser (Thermo Finnigan, Italy) following the manufacturer's standard procedures, with L-Aspartic Acid, Atropine and Nicotinamide as standards for $\mathrm{C}, \mathrm{H}$ and N. Birch and Pasta were used as standards for sulphur determination with the addition of vanadium pentoxide catalyst and a desiccating column to remove the $\mathrm{H}$ peak. For marine samples the elemental composition of the ashed sample was also analysed. Higher heat value 
(calorific value, CV) was determined using a bomb calorimeter (Cal2K Eco, South Africa) standardised with $0.5 \mathrm{~g}$ benzonic acid.

\subsection{Biochemical methane potential (BMP)}

This assay was carried out in 0.5-litre digesters which were mixed manually once per day. Inoculum was taken from a mesophilic digester treating municipal wastewater biosolids (Millbrook wastewater treatment plant, Southampton, UK). The inoculum-to-substrate ratios used were around 4:1 based on the VS content of the materials [33]. Initial tests were carried out in triplicate for a period of 28 days against blanks with no substrate added and against a positive cellulose control (C6288, Sigma-Aldrich Ltd, UK). Some of the samples were then tested a second time for a period of 90 days to confirm the ultimate BMP values. All tests were carried out at $37 \pm 1{ }^{\circ} \mathrm{C}$. Biogas was collected in 1-litre collection cylinders using a $75 \%$ sodium chloride barrier solution adjusted to $\mathrm{pH} 2$ with sulphuric acid to minimise losses of $\mathrm{CH}_{4}$ through dissolution. Biogas composition was analysed each time the collection cylinder was emptied. The methane content of the sample was measured by gas chromatography, using a Varian star $3400 \mathrm{CX}$ Chromatograph with a mixed gas standard of $65 \% \mathrm{CH}_{4}$ and $35 \%$ $\mathrm{CO}_{2}(\mathrm{v} / \mathrm{v})$ for calibration (BOC, UK). The volume of methane was calculated by multiplying the dry biogas volume (i.e. after deduction of the calculated volume of water vapour) by the percentage of methane, corrected so that $\% \mathrm{CH}_{4}$ plus $\% \mathrm{CO}_{2}=100 \%$. All gas volumes reported are corrected to standard temperature and pressure (STP) of $0{ }^{\circ} \mathrm{C}, 101.325 \mathrm{kPa}$ as described by Walker et al. (2009) [33].

\subsection{Calculation of theoretical methane yield, calorific value and biodegradability}

Measured BMP values were compared to the theoretical methane potential (TMP) calculated from the Buswell equation [34] shown in equation 2, with elemental composition data taken from direct measurement of $\mathrm{C}, \mathrm{H}, \mathrm{N}$ and $\mathrm{S}$, and $\mathrm{O}$ obtained by difference, on a \% VS basis.

$\mathrm{C}_{\mathrm{c}} \mathrm{H}_{\mathrm{h}} \mathrm{O}_{\mathrm{o}} \mathrm{N}_{\mathrm{n}} \mathrm{S}_{\mathrm{s}}+1 / 4(4 \mathrm{c}-\mathrm{h}-2 \mathrm{o}+3 \mathrm{n}+2 \mathrm{~s}) \mathrm{H}_{2} \mathrm{O} \rightarrow 1 / 8(4 \mathrm{c}-\mathrm{h}+2 \mathrm{o}+3 \mathrm{n}+2 \mathrm{~s}) \mathrm{CO}_{2}+1 / 8(4 \mathrm{c}+\mathrm{h}-$ $2 \mathrm{o}-3 \mathrm{n}-2 \mathrm{~s}) \mathrm{CH}_{4}+\mathrm{nNH}_{3}+\mathrm{sH}_{2} \mathrm{~S}$

Theoretical calorific values for the samples were calculated using equation 3 [35].

Higher heat value in $\mathrm{MJ} \mathrm{kg}^{-1} \mathrm{VS}=(34.1 \mathrm{C}+102 \mathrm{H}+6.3 \mathrm{~N}+19.1 \mathrm{~S}-9.85 \mathrm{O}) / 100$

The higher heat value of $\mathrm{CH}_{4}$ was taken as $39.84 \mathrm{MJ} \mathrm{m}^{-3}$ at STP.

Potential methane productivity was calculated based on the biomass yield of micro-algal VS as determined by growth rate measurements. This does not give an absolute value, as in practice biomass yield depends on a large number of factors including local climatic conditions, bioreactor design and mode of operation. The relative value obtained under the growth conditions used does, however, provide a means of comparing methane yields under standardised conditions for estimation of potential methane productivity expressed in $\mathrm{L} \mathrm{CH}_{4}$ $\mathrm{L}^{-1}$ culture medium day ${ }^{-1}$.

Biodegradability of the micro-algal samples was assessed from BMP kinetic data using the pseudo-parallel first order model shown in equation 4

$Y=Y_{\max }\left(1-P e^{-k 1}-(1-P) e^{-k 2}\right)$ 
where $Y\left(\mathrm{~L} \mathrm{CH}_{4} \mathrm{~g}^{-1} \mathrm{VS}\right)$ is the specific methane production at time $t$ (day), $Y_{\max }$ is the measured or estimated ultimate methane yield ( $\left.\mathrm{L} \mathrm{CH}_{4} \mathrm{~g}^{-1} \mathrm{VS}\right), k_{l}$ is the first order rate constant $\left(\right.$ day $\left.^{-1}\right)$ for readily biodegradable material, $k_{2}$ is the first order rate constant $\left(\right.$ day $\left.^{-1}\right)$ for less readily biodegradable material and $P$ is the proportion of readily biodegradable material [36]. Values of kinetic parameters were estimated by sequential variation of $P, k_{1}$ and $k_{2}$ to 2 decimal places to give the maximum coefficient of correlation $\left(\mathrm{R}^{2}\right)$ with the experimental data using the method of least squares.

\section{$3 \quad$ Results and discussion}

\subsection{Characterisation}

Table 1 shows the results of characterisation of the different samples. VS content as a proportion of TS ranged widely for the laboratory-grown cultures, from around $50.4 \%$ for Dunaliella sp. to $94.7 \%$ for $C$. vulgaris. The difference in values for the two large-scale samples may reflect the different cultivation systems, with the open raceway subject to both ingress of wind-blown grit and increases in salt concentration due to evaporation. After centrifugation the laboratory-grown samples had moisture contents from 68.1-78.8\%. If the VS content is corrected to allow for the estimated quantity of sea salt present in this moisture fraction in each sample, the revised VS content of the marine samples was 73.4, 68.2, 54.7 and $86.4 \%$ of TS for I. galbana, T. pseudonana, Dunaliella sp. and N. occulata respectively, with the values for all but $N$. occulata still below those for the two laboratory-grown freshwater species. Low VS/TS ratios for marine and diatom species have been reported elsewhere [16, 37-40], but Zhu and Lee [41] also showed that the TS content of unwashed samples may be as much as $20 \%$ higher than washed cells. The value for N. occulata was similar to that reported in other studies [16].

Table 1 Characteristics of 8 micro-algal samples

\begin{tabular}{|c|c|c|c|c|c|c|c|c|c|}
\hline & VS & TKN & $\mathrm{CV}$ & & Elemental co & npositic & (\% of VS) & & \\
\hline Species & $(\% \mathrm{TS})$ & $\begin{array}{c}\% \mathrm{~N} \text { of } \\
\mathrm{VS}\end{array}$ & $\begin{array}{l}\mathrm{MJ} \\
\mathrm{kg}^{-1} \\
\mathrm{VS}\end{array}$ & $\mathrm{C}$ & $\mathrm{H}$ & $\mathrm{O}^{\mathrm{a}}$ & $\mathrm{N}$ & S & $\mathrm{C} / \mathrm{N}^{\mathrm{b}}$ \\
\hline I. galbana & $67.2 \pm 0.61$ & $6.61 \pm 0.01$ & 23.4 & $52.94 \pm 0.65$ & $7.93 \pm 0.16$ & 28.49 & $6.71 \pm 0.06$ & $4.02 \pm 0.04$ & 8.0 \\
\hline T. pseudonana & $59.8 \pm 1.24$ & $6.29 \pm 0.01$ & 21.9 & $47.68 \pm 0.34$ & $7.67 \pm 0.02$ & 34.44 & $5.49 \pm 0.04$ & $3.91 \pm 0.13$ & 7.6 \\
\hline Dunaliella sp. & $50.4 \pm 0.65$ & $6.10 \pm 0.01$ & 20.0 & $43.71 \pm 0.62$ & $7.99 \pm 0.08$ & 36.75 & $6.90 \pm 0.04$ & $5.45 \pm 0.68$ & 7.2 \\
\hline N. occulata & $80.3 \pm 0.48$ & $4.66 \pm 0.01$ & 21.6 & $50.66 \pm 0.54$ & $7.18 \pm 0.07$ & 35.66 & $4.67 \pm 0.04$ & $1.85 \pm 0.06$ & 10.9 \\
\hline C. vulgaris & $94.7 \pm 0.32$ & $5.15 \pm 0.02$ & 25.0 & $52.97 \pm 0.51$ & $7.91 \pm 0.08$ & 33.13 & $4.68 \pm 0.03$ & $0.84 \pm 0.02$ & 10.3 \\
\hline Scenedesmus sp. & $83.9 \pm 0.05$ & $7.36 \pm 0.00$ & 21.5 & $46.51 \pm 0.29$ & $6.89 \pm 0.07$ & 38.82 & $6.32 \pm 0.03$ & $0.42 \pm 0.02$ & 6.3 \\
\hline PBR (FD) & $82.0 \pm 0.03$ & $8.40 \pm 0.00$ & 24.4 & $54.18 \pm 0.65$ & $6.77 \pm 0.11$ & 29.86 & $9.63 \pm 0.10$ & $0.79 \pm 0.02$ & 6.4 \\
\hline Raceway & $39.4 \pm 0.17$ & $9.95 \pm 0.00$ & 21.3 & $45.51 \pm 0.87$ & $8.98 \pm 0.09$ & 34.60 & $8.66 \pm 0.13$ & $0.96 \pm 0.10$ & 4.6 \\
\hline
\end{tabular}

Carbon content ranged from 43.7-54.2\% on a VS basis. The nitrogen content as determined by elemental analysis showed reasonably good agreement with TKN concentrations, which were between 4.7-9.6\% VS. As expected, the resulting $\mathrm{C} / \mathrm{N}$ ratios were all well below the recommended range of 20-30 for anaerobic digestion, and similar to those reported in the literature [26]. Sulphur concentrations were higher in marine than in freshwater species. Calorific values ranged from 8.4-23.6 kJ g-1 $\mathrm{TS}$, reflecting the different proportions of inorganic material present in the samples. On a VS basis the CV was more uniform at 20.0- 
$25.0 \mathrm{~kJ} \mathrm{~g}^{-1} \mathrm{VS}$, reflecting the similar elemental composition of the organic fractions. $\mathrm{C}, \mathrm{H}$, and $\mathrm{N}$ in the ashed components of the marine species were negligible $(<0.25 \% \mathrm{TS})$.

\subsection{BMP and theoretical energy values}

The two BMP assays were run consecutively, in each case using fresh inoculum taken from the same source within a one-month period. The BMP value for the cellulose controls in the 28-day and 90-day tests were $0.412 \pm 0.007$ and $0.415 \pm 0.004 \mathrm{~L} \mathrm{CH}_{4} \mathrm{~g}^{-1}$ VS respectively, both very close to the theoretical value, with the difference of $<0.5 \%$ giving confidence in the comparability of results from the two assays.

The results of the 28-day test are shown in Figure 1a: it can be seen that the cumulative specific methane yield of some samples was still increasing by the end of the test, whilst other appeared to have reached their maximum. For this reason a second test was carried out on selected samples over a more extended period. Of the samples for which it appeared possible to determine a BMP in the 28-day test, the two marine species $T$. pseudonana and $I$. galbana had the highest values at 0.435 and $0.349 \mathrm{~L} \mathrm{CH}_{4} \mathrm{~g}^{-1} \mathrm{VS}$, respectively. This was considerably greater than the BMP of $0.276 \mathrm{~L} \mathrm{CH}_{4} \mathrm{~g}^{-1} \mathrm{VS}$ for Dunaliella sp., while $N$. occulata had not achieved its maximum potential in this period. The freshwater samples of $C$. vulgaris and the large-scale raceway and PBR materials did not reach their final BMP values but the specific methane yields after 28-days were 0.300, 0.216 and $0.130 \mathrm{~L} \mathrm{CH}_{4} \mathrm{~g}^{-1} \mathrm{VS}$, respectively.

Figure $1 \mathrm{~b}$ shows the results for cumulative specific methane yield in the 90 -day BMP test. $N$. occulata showed an increase of $\sim 22 \%$ above the 28 -day value, with a cumulative specific methane production of $0.231 \mathrm{~L} \mathrm{~g}^{-1} \mathrm{VS}_{\text {day }}{ }^{-1}$ which was taken as the BMP value. The difference for the freshwater species $C$. vulgaris was within the standard deviations of the tests, and the final BMP was therefore taken as $0.307 \mathrm{~L} \mathrm{CH}_{4} \mathrm{~g}^{-1} \mathrm{VS}$ based on the 90-day test results. A laboratory-grown culture of Scenedesmus sp. was also tested and had a BMP of $0.261 \mathrm{~L} \mathrm{CH}_{4} \mathrm{~g}^{-1} \mathrm{VS}$.

The freeze-dried sample from the PBR and the fresh frozen raceway sample had measured 90-day BMP values of 0.161 and $0.220 \mathrm{~L} \mathrm{CH}_{4} \mathrm{~g}^{-1} \mathrm{VS}$, respectively, considerably below that of the laboratory-cultured Scenedesmus. The BMP of the raceway sample was also lower than might be expected based on the individual BMPs for laboratory-grown Chlorella and Scenedesmus, the two species comprising the main fractions of the raceway population. The extended test gave an increase of $\sim 24 \%$ in the specific methane yield of the PBR sample, which appeared to be still rising very slightly even after 90 days; but the raceway sample showed no significant change from the 28-day result and the 90-day value was therefore taken as the measured BMP.

Predicted TMP values based on the Buswell equation were between 0.45-0.57 $\mathrm{L} \mathrm{CH}_{4} \mathrm{~g}^{-1} \mathrm{VS}$. Measured BMP values ranged from $30.0-88.2 \%$ of the TMP, indicating widely different degrees of VS breakdown. Measured CV expressed on a VS basis showed reasonable agreement with the theoretical CV values, giving confidence in the elemental analysis results. The marine species I. galbana and T. pseudonna had the greatest apparent conversion efficiency of measured $\mathrm{CV}$ into methane, at $59.5 \%$ and $79.2 \%$ respectively, whereas the conversion efficiencies for $N$. occulata and the freshwater species were lower at $26.4 \%$ to $49.0 \%$ (Table 2). 


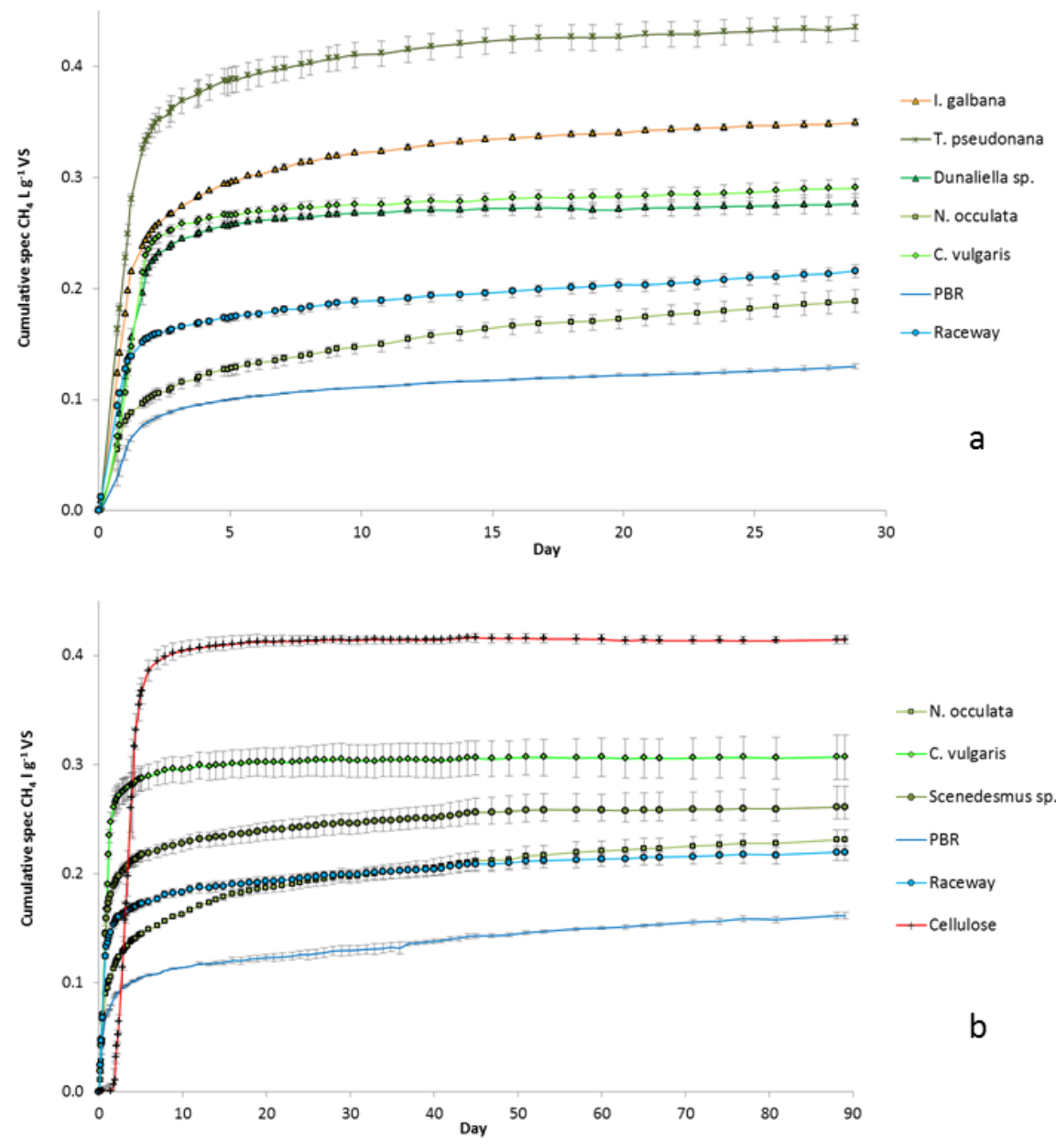

Figure 1 Cumulative net specific methane yield of marine and freshwater micro-algae (a) 28day BMP test, (b) 90-day BMP test.

Table 2 Measured BMP, TMP and calorific values

\begin{tabular}{|c|c|c|c|c|c|c|c|c|}
\hline \multirow[t]{2}{*}{ Species } & \multicolumn{3}{|c|}{ Measured BMP } & \multirow{2}{*}{$\begin{array}{c}\mathrm{TMP} \\
\mathrm{L} \mathrm{CH}_{4} \mathrm{~g}^{-1} \\
\mathrm{VS}\end{array}$} & \multirow{2}{*}{$\begin{array}{c}\text { Theoretical } \\
\text { CV } \\
\mathrm{kJ} \mathrm{g}^{-1} \mathrm{VS}\end{array}$} & \multirow{2}{*}{$\begin{array}{c}\text { BMP as } \% \\
\text { of TMP } \\
\%\end{array}$} & \multirow{2}{*}{$\begin{array}{c}\text { Energy value } \\
\text { of } \mathrm{CH}_{4} \text { from } \\
\text { BMP } \\
\mathrm{kJ} \mathrm{g}^{-1} \mathrm{VS}\end{array}$} & \multirow[t]{2}{*}{$\begin{array}{l}\% \text { of CV } \\
\text { converted } \\
\text { to } \mathrm{CH}_{4}{ }^{\mathrm{c}}\end{array}$} \\
\hline & $\mathrm{LC}$ & & VS & & & & & \\
\hline I. galbana & 0.349 & \pm & 0.004 & 0.568 & 24.5 & 61.5 & 13.9 & 59.5 \\
\hline T. pseudonana & 0.435 & \pm & 0.017 & 0.493 & 21.8 & 88.2 & 17.3 & 79.2 \\
\hline Dunaliella sp. & 0.276 & \pm & 0.011 & 0.455 & 20.9 & 60.7 & 11.0 & 55.1 \\
\hline N. occulata ${ }^{b}$ & 0.231 & \pm & 0.010 & 0.516 & 21.7 & 44.7 & 9.2 & 42.6 \\
\hline C. vulgaris $^{b}$ & 0.307 & \pm & 0.029 & 0.566 & 23.4 & 54.2 & 12.2 & 49.0 \\
\hline Scenedesmus sp. & 0.261 & \pm & 0.017 & 0.445 & 19.6 & 58.7 & 10.4 & 48.3 \\
\hline $\operatorname{PBR}(\mathrm{FD})^{\mathrm{b}}$ & 0.161 & \pm & 0.017 & 0.537 & 23.1 & 30.0 & 6.4 & 26.4 \\
\hline Raceway ${ }^{b}$ & 0.220 & \pm & 0.007 & 0.492 & 22.1 & 44.7 & 8.8 & 41.0 \\
\hline
\end{tabular}

${ }^{\mathrm{a}} 28$-day test; ${ }^{\mathrm{b}} 90$-day test value; ${ }^{\mathrm{c}}$ based on measured CV

The BMP values for freshwater $C$. vulgaris and Scenedesmus sp. obtained in the current work are typical of median values found in the literature [26, 28, 42-44]. Fewer results are available for marine species, but for the genera above the values of $0.408 \mathrm{~L} \mathrm{CH}_{4} \mathrm{~g}^{-1}$ VS have been reported for Isochrysis sp. [43], 0.38 and $0.265 \mathrm{~L} \mathrm{CH}_{4} \mathrm{~g}^{-1} \mathrm{VS}$ for Thalassiosira weissflogii [38, 43], 0.204 and $0.323 \mathrm{~L} \mathrm{CH}_{4} \mathrm{~g}^{-1} \mathrm{VS}$ for Dunaliella salina [40, 42], and 0.204 $\mathrm{L} \mathrm{CH}_{4} \mathrm{~g}^{-1}$ VS for N. occulata [37]. 


\subsection{Methane production kinetics}

The kinetic coefficients obtained from the methane potential tests are shown in Table 3. As these are from batch testing they cannot be used directly for continuous or semi-continuous digestion, but they do indicate the amenability of the material to digestion and the type of reactor and retention time likely to be required in a full-scale system. Several species showed a small delay in the onset of rapid gas production, especially in the first BMP test, and the fit of the kinetic models for I. galbana and Dunaliella sp. was considerably improved by imposing a lag phase of 0.3 and 0.5 days, respectively (Figure 2).
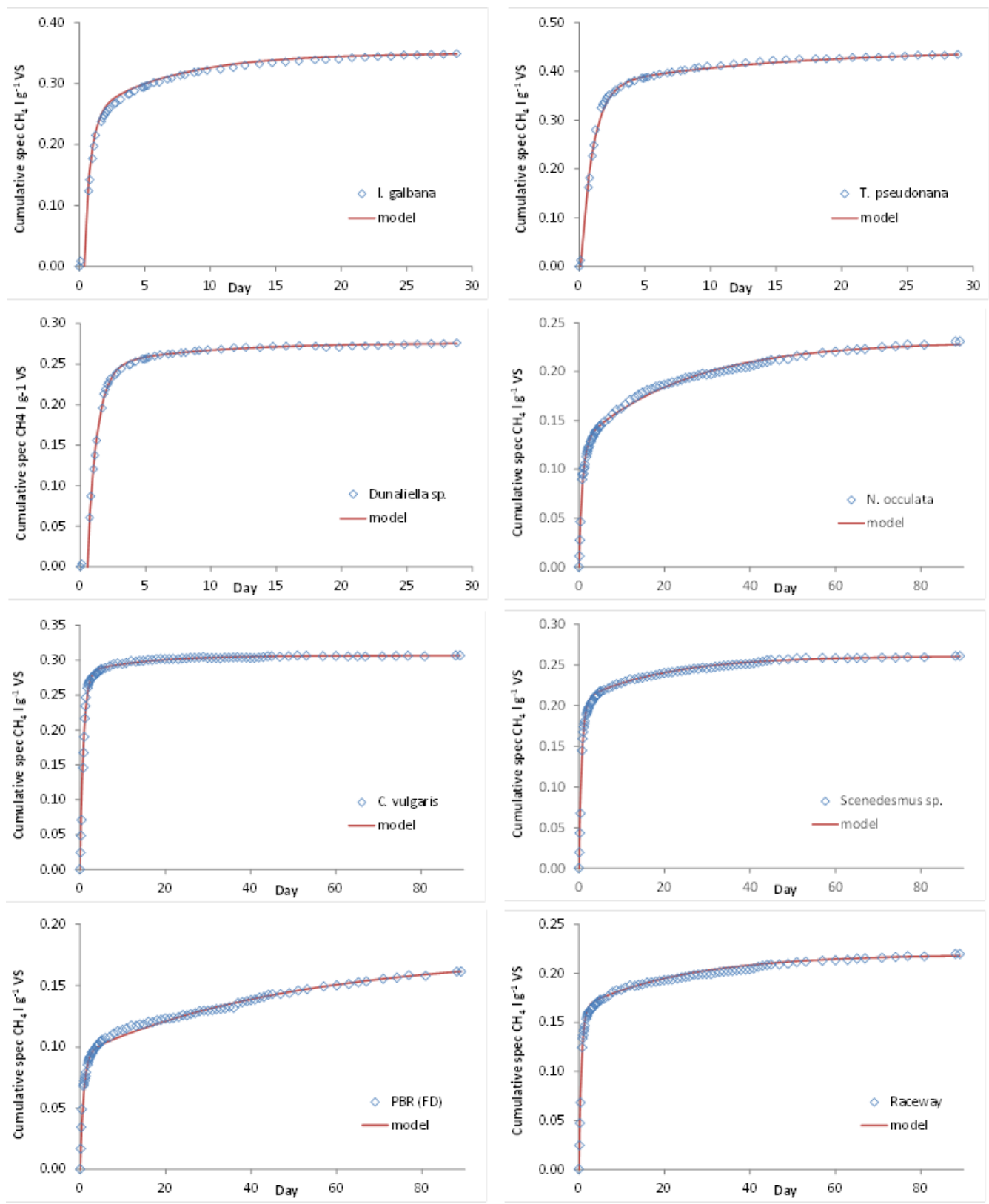

Figure 2 Cumulative net specific methane yield of marine and freshwater micro-algae (average of experimental data points for replicates) with kinetic models

The proportion of anaerobically biodegradable material that was readily degradable was over $80 \%$ for T. pseudonana, Dunaliella sp. and C. vulgaris, and over $70 \%$ for I. galbana, 
Scenedesmus sp. and the raceway sample; while for $N$. occulata and the PBR sample it was much lower. Values for $k_{l}$ ranged from 1.08-1.93 day $^{-1}$ with the majority lying between 1.21.5 day $^{-1}$, indicating that the properties of the readily degradable fraction were similar in these cases. Values of $k_{2}$ showed more variability, ranging from 0.02-0.15 day ${ }^{-1}$. The PBR sample had the lowest values for $k_{1}$ and $k_{2}$. Samples tested for both 28 and 90 days showed similar kinetic coefficients in each case, giving some confidence in the results: final BMP values from the two tests were also similar apart from for $N$. occulata. The modelled BMP values were mainly similar to the experimental results, but modelling gave slightly higher BMPs for I. galbana, T. pseudonana and the PBR sample, indicating the need for a longer test duration in these cases.

Table 3 Specific methane yields and kinetic constants obtained from modelling

\begin{tabular}{|c|c|c|c|c|c|c|c|}
\hline & $\begin{array}{c}\mathbf{Y}_{\max } \\
\left(\mathrm{L} \mathrm{CH}_{4} \mathrm{~g}^{-1} \mathrm{VS}\right)\end{array}$ & $\mathbf{P}$ & $\begin{array}{c}\begin{array}{c}\mathbf{k}_{\mathbf{1}} \\
\text { day }^{-1}\end{array} \\
\end{array}$ & $\begin{array}{r}\begin{array}{c}\mathbf{k}_{\mathbf{2}} \\
\text { day }^{-1}\end{array} \\
\end{array}$ & $\mathbf{R}^{2 \mathrm{a}}$ & $\begin{array}{l}\text { Lag } \\
\text { day }\end{array}$ & Comment \\
\hline \multicolumn{8}{|l|}{ 28-day values } \\
\hline I. galbana & 0.350 & 0.71 & 1.93 & 0.15 & 0.9989 & 0.3 & Almost at max in 28-day BMP \\
\hline T. pseudonana & 0.445 & 0.83 & 1.08 & 0.07 & 0.9937 & 0.1 & Almost at max in 28-day BMP \\
\hline Dunaliella sp. & 0.276 & 0.89 & 1.36 & 0.13 & 0.9980 & 0.5 & At max in 28-day test \\
\hline N. occulata & 0.220 & 0.47 & 1.26 & 0.05 & 0.9977 & 0.1 & Still rising in 28 -day test \\
\hline C. vulgaris & 0.300 & 0.86 & 1.38 & 0.04 & 0.9882 & 0.5 & Still rising in 28 -day test \\
\hline PBR (FD) & 0.175 & 0.53 & 1.08 & 0.02 & 0.9942 & 0.3 & Still rising in 28 -day test \\
\hline Raceway & 0.220 & 0.70 & 1.55 & 0.06 & 0.9972 & $\leq 0.1$ & Still rising in 28 -day test \\
\hline \multicolumn{8}{|l|}{ 90-day values } \\
\hline N. occulata & 0.231 & 0.55 & 1.20 & 0.04 & 0.9955 & $\leq 0.1$ & Possibly still rising slightly \\
\hline C. vulgaris & 0.307 & 0.92 & 1.22 & 0.07 & 0.9905 & - & - \\
\hline Scenedesmus sp. & 0.261 & 0.77 & 1.70 & 0.05 & 0.9951 & $\leq 0.1$ & - \\
\hline PBR (FD) & 0.175 & 0.54 & 1.21 & 0.02 & 0.9945 & - & Still rising slightly at end of test \\
\hline Raceway & 0.220 & 0.75 & 1.66 & 0.04 & 0.9956 & $\leq 0.1$ & - \\
\hline
\end{tabular}

\subsection{Growth rate, biomass yield and effect on overall methane productivity}

Growth rates for the laboratory-grown cultures were between 0.61-0.77 day $^{-1}$ with estimated biomass yields from $0.15-0.19 \mathrm{~g} \mathrm{VS} \mathrm{L}^{-1} \mathrm{day}^{-1}$ (Table 4). Methane productivity per unit of culture volume ranged from $0.04-0.08 \mathrm{~L} \mathrm{CH}_{4} \mathrm{~L}^{-1}$ day ${ }^{-1}$. The highest value was for $T$. pseudonana, and the lowest for Dunaliella sp., both of which are marine species. N. occulata and Dunaliella sp. had similar methane productivities, with the lower methane potential of $N$. occulata being compensated for by its higher growth rate. The two freshwater species had similar growth rates but methane productivity was affected by both the biomass yield and the BMP value: Scenedesmus sp. was not only poorly degradable, as also reported by others [26, 43, 44], but also had a lower VS/TS ratio in the harvested biomass. The same was true for the marine species I. galbana and Dunaliella sp., where the growth rates were similar but the VS of the Dunaliella sp. proved recalcitrant to conversion in the BMP test.

The growth rates measured here were in most cases lower than typical maximum growth rates reported in the literature, which range e.g. from 0.55-0.80 day ${ }^{-1}$ for I. galbana, 1.33-2.52 day ${ }^{-}$ ${ }^{1}$ for T. pseudonana, 0.77-1.00 day ${ }^{-1}$ for Dunaliella tertiolecta, 1.59-2.90 $\mathrm{day}^{-1}$ for $C$. vulgaris and 1.34-2.2 day $^{-1}$ for Scenedesmus sp. [45]. Differences in growth media composition with up to an order of magnitude lower nitrogen and phosphorus content in the media used, the type of culture vessels and of lighting used are all likely to contribute to the lower growth rates observed here. 
Reported data for the raceway sample [30] indicates a biomass yield of around $0.05 \mathrm{~g} \mathrm{VS} \mathrm{L}^{-1}$ day $^{-1}$, giving a methane productivity of only around $0.01 \mathrm{~L} \mathrm{CH}_{4} \mathrm{~L}^{-1}$ day $^{-1}$ for the period considered.

Table 4 Growth rates and biomass yields with potential methane production per litre of culture per day for selected samples of freshwater and marine micro-algae.

\begin{tabular}{lcccc}
\hline Species & $\begin{array}{c}\text { Modelled BMP } \\
\mathrm{LCH}_{4} \mathrm{~g}^{-1} \mathrm{VS}\end{array}$ & $\begin{array}{c}\text { Growth rate } \\
\mathrm{day}^{-1}\end{array}$ & $\begin{array}{c}\text { Biomass yield } \\
\mathrm{g} \mathrm{VS} \mathrm{l}^{-1} \mathrm{day}^{-1(\mathrm{a})}\end{array}$ & $\begin{array}{c}\text { Methane productivity } \\
\mathrm{LCH}_{4} \mathrm{~L}^{-1} \text { day }^{-1}\end{array}$ \\
\hline I. galbana & 0.350 & 0.61 & 0.153 & 0.053 \\
T. pseudonana & 0.445 & 0.71 & 0.178 & 0.079 \\
Dunaliella sp. & 0.276 & 0.59 & 0.148 & 0.041 \\
N. occulata & 0.231 & 0.77 & 0.193 & 0.045 \\
C. vulgaris & 0.307 & 0.75 & 0.187 & 0.057 \\
Scenedesmus sp. & 0.261 & 0.76 & 0.189 & 0.049 \\
\hline
\end{tabular}

${ }^{\mathrm{b}}$ Assuming 12 hours of growth per day and harvest concentration $0.5 \mathrm{~g} \mathrm{VS} \mathrm{L}^{-1}$.

\subsection{Discussion}

The current work aimed to test a screening protocol for comparative assessment of microalgal biomass, for use prior to full testing in continuous digestion trials. There is as yet no single widely-accepted protocol or duration for a BMP assay for biomass samples, although the International Water Association's Task Group on Anaerobic Biodegradation, Activity and Inhibition (ABAI) has provided guidelines on key requirements for a test protocol [46]. BMP assays over fixed or short intervals do not necessarily provide reliable comparative values, especially for micro-algal material which may continue to be degraded over long periods. Despite this is it relatively common to see BMP values reported in the literature from tests carried out for short periods when cumulative methane production is still increasing at the end of the assay. The German VDI 4630 standard says "the test should be terminated when the daily biogas rate is equivalent to only $1 \%$ of the total volume of biogas produced up to that time", and suggests a typical duration of 20-40 days: for slow-degrading substrates, however, a further 25 days at $1 \%$ per day may represent be significant increment on the BMP value. In most cases the 28-day BMP test used here gave a reasonable approximation of the final values obtained from the 90-day test and from modelling, providing some confidence in the method and in the validity of the results. When using this modelling approach, however, it is essential to ensure that the cumulative methane yield is at or close to its maximum by the end of the test period: the model used can provide a very accurate fit to a full set of data but performs poorly in predicting the final BMP value from an incomplete run, due to the difficulty of parameter estimation.

The range of BMP values found in the present work was wide, even when reported on a VS basis, indicating that a proportion of the organic matter is either non-biodegradable or protected from biodegradation by incorporation into structural cell material: this is analogous to the situation in terrestrial plants, in which the cellulose in woody biomass is protected by a non-degradable lignin fraction. Although lignin is not a component of algal cells, similar cross-linked macromolecular structures exist in the cell walls offering protection to the cell contents or simply making the cell wall carbon non-digestible [47, 48]. Mussgnug et al. [42] noted that Scenedesmus obliquus and Chlorella kessleri have hemicellulose-containing carbohydrate-based walls which make them tougher to digest, S. obliquus especially so as it contains a sporopollenin-like biopolymer. A wide range of microalgal cell wall compositions and structures have been reported in the literature, some of which reflect intrinsic differences 
between species [47, 49]. In a detailed study of the susceptibility of $C$. vulgaris and other micro-algae to enzymatic degradation Gerken et al. [48] also noted, however, that major changes in cell wall composition might depend on very small differences in growth conditions, as well as on factors such as the culture age. To draw firm conclusions on the optimum strategies to enhance anaerobic degradation, further fundamental work is required looking both at the composition and molecular structure of micro-algal cells, and at factors affecting this. The greater recalcitrance of the PBR and raceway samples, indicated by their low BMP values, may be a response to more challenging growth conditions in large-scale systems, including factors such as predation and turbulence-induced shear. Although cellulose was used as a standard in the BMP test to indicate inoculum viability and response, the BMP value for cellulose as a pure chemical is usually higher than that found naturally as it is not protected by other composite-forming macro-molecules.

The laboratory-grown species tested showed a range of growth rates under the conditions used, which influenced the overall methane productivity. Although BMP values are often quoted with the aim of providing an indication of the energy potential of a biomass crop, it is equally or even more important to consider the overall biomass productivity per unit of production capacity. This concept is commonly applied when looking at terrestrial energy crops, where net energy production is considered in GJ per hectare-year. The combination of growth rates and methane yields obtained under standard conditions used in the present work provides a possible approach to estimating equivalent values for algal biomass crops; but further data on the energy inputs to algal cultivation systems are needed for determination of overall energy balances $[1,5]$.

In most cases the growth rates obtained in the conditions used were lower than literature values for maximum growth rates, for the reasons already noted above. When considered as biomass yields, however, the values obtained are similar to those that might be expected from larger-scale open systems. Algal biomass yields in raceway systems are normally quoted on an areal rather than a volumetric basis. If the volumetric biomass yields achieved are converted to areal values by assuming a typical water depth of $0.2 \mathrm{~m}$, the results would range from 30-39 $\mathrm{g} \mathrm{VS} \mathrm{m}^{2} \mathrm{day}^{-1}$, in the mid-to-upper range of reported values for open raceway systems [30, 50]. For the purposes of offering a practical testing protocol, the growth conditions used may therefore be considered an appropriate choice, as the micro-algal yields achieved are representative of those in large-scale systems that are operating very effectively.

Biomass yields for the laboratory-grown $C$. vulgaris and Scenedesmus sp. were much higher than those estimated for the raceway culture. In large-scale systems there are likely to be limitations due to factors such as light, temperature, dissolved oxygen concentration and the applied dilution rate. It is not known how or to what extent these factors may also affect the degradability of the micro-algal biomass, and hence its BMP. The BMP value of the freezedried PBR sample was much lower than either the laboratory culture of Scenedesmus sp. or the raceway sample, however, with one possible explanation being the loss of more readilydegradable volatile organic compounds through sublimation during the freeze-drying process. The low values found for the kinetic constants $P$ and $k_{l}$ in modelling the PBR sample may give support to this view. Reductions in BMP values have also been reported after oven drying of Chlorella kessleri and Chlamydomonas reinhardtii [42]. Further work is clearly needed on the likely impact both of growth conditions and of post-harvest storage and processing on digestibility. 
The marine species $T$. pseudonana appeared to be the first choice for methane production, with an overall energy conversion of $79.2 \%$ of its calorific value and a good biomass yield. It should be remembered, however, that good performance in laboratory conditions may not translate to large-scale systems where ease of cultivation, sustainable high productivity and resistance to predation are also key factors. The next best performances were from the freshwater $C$. vulgaris, followed by the marine I. galbana. The marine Dunaliella sp. and $N$. occulata both had low methane productivity. While $N$. occulata required 77 days to reach $90 \%$ of its BMP value, however, Dunaliella sp. and I. galbana achieved this within the first 4 and 8 days of the test respectively (Figure 2): the differences are clearly visible in the values of the kinetic coefficients $P$ and $k_{l}$ in each case. These differences in degradation behaviour may have significant implications for the required retention time, reactor volume and operating costs in large-scale continuous digestion systems. It is also notable that the BMP value for $N$. occulata was much lower than for Dunaliella sp., while the value for I. galbana was only $80 \%$ that of T. pseudonana: the four species achieved respectively 44.7, 60.7, 61.52 and $88.2 \%$ of their TMP values (Table 2). The development of effective pre-treatments to enhance degradability is thus likely to have a major influence on the choice of species, especially given the variability of reported BMP values even for a single species [26, 43, 44]. Harvesting and storage methods may themselves act as pre-treatments [48, 51], with both freezing and centrifugation potentially capable of rupturing cells and thus leading to increased methane yields or improved production kinetics. T. pseudonana has a solid silica cell wall consisting of two frustules, which can open during centrifugation: this may have contributed to the high values for BMP and for TMP conversion on a VS basis compared to those for the micro-algae with organic cell walls in the current study. The differing BMP values of 0.265 and $0.38 \mathrm{~L} \mathrm{CH}_{4} \mathrm{~g}^{-1}$ VS reported for the diatom Thalassiosira weissflogii [38, 43] could thus reflect whether the harvesting technique was able to cause frustule separation. Raceway material as used in the current trial was tested fresh and after freezing, however, and showed only a small increase in BMP value (unpublished data, University of Southampton).

Ammonia is known to be inhibitory to methanogenesis, though there is some debate about toxicity thresholds, in part because microbial populations can acclimatise to high concentrations to some extent [25]. The Buswell equation allows estimation of the theoretical maximum amount of ammonia that could be produced from complete degradation of the micro-algal biomass. For the samples tested, assuming an algal biomass feedstock VS concentration of $5 \%$ the maximum theoretical TAN concentration would range from $2.3 \mathrm{~g} \mathrm{~N}$ $\mathrm{L}^{-1}$ for $N$. occulata to $5.0 \mathrm{~g} \mathrm{~N} \mathrm{~L}^{-1}$ for the raceway sample. These values are below the toxic range for mesophilic digestion, but would be problematic in thermophilic digestion. At a feedstock VS content of $10 \%$ the maximum TAN concentrations would double, and could cause the onset of inhibition in mesophilic conditions. Alternatively, a crude estimate could be made of the maximum solids concentration at which the micro-algal material could be digested without exceeding a limiting TAN concentration, based on the total $\mathrm{N}$ or TKN content and the degree of breakdown of the biomass as indicated by the proportion of $\mathrm{CV}$ recovered as methane in the BMP test. For the samples tested, based on measured TKN and BMP values and assuming limiting TAN concentrations of 6.0 and $2.5 \mathrm{~g} \mathrm{~N} \mathrm{~kg}^{-1} \mathrm{WW}$ for stable mesophilic and thermophilic digestion respectively, the maximum acceptable feedstock VS content would range from $12.0 \% \mathrm{VS}$ for T. pseudonana to $30.2 \% \mathrm{VS}$ for $N$. occulata in mesophilic conditions, and from 5.0 to $12.6 \%$ VS in thermophilic conditions, respectively. These estimates do not take into account the reduction in the mass of digestate produced compared to that of feedstock added. This has the effect of increasing the digestate TAN concentration: a correction for this can also be estimated, based on the mass of biogas 
produced in the BMP test. In practice, however, this method of estimation of maximum feedstock concentrations is highly conservative, as some of the ammonia released is taken up to meet the growth needs of the anaerobic microbial consortium. The quantity of anaerobic microbial biomass and the digestate TAN concentration in a digester are functions of the organic loading rate (OLR), the hydraulic retention time (HRT) and the type of substrate [52], but relationships between these factors are not sufficiently well understood to allow more accurate predictions of digestate TAN. It should be noted, however, that improving the degree of biomass degradation may lead to higher TKN conversion, and thus to lower optimum post-harvest concentrations based on the permissible TAN concentration [15]. The low $\mathrm{C} / \mathrm{N}$ ratio for all the algal species suggests that ammonia toxicity/inhibition may be a risk in non-acclimatised systems at the moderate to high algal biomass feedstock concentrations required to reach high OLR [18]. This could be avoided by co-digestion with another waste stream with lower TKN content or, for readily degradable algal species, by using a more dilute feedstock with a short HRT [18]. The latter option would reduce harvesting costs, but would increase the digester and feedstock heating requirement per unit of biomass and thus affect the overall energy balance.

Although three of the marine species appeared to be good candidates for methane production in continuous culture the micro-algal cells contain sulphur, which is also present in appreciable concentrations as sulphate in the seawater (on average $2800 \mathrm{mg} \mathrm{L}^{-1}$ as $\mathrm{SO}_{4}$ ). In anaerobic digestion sulphate will be converted to hydrogen sulphide by sulphate-reducing bacteria (SRB), and at lower concentrations the competition for substrate between SRB and methanogens will reduce methane productivity. At higher concentrations sulphides are inhibitory to methanogenesis [25]. The speciation and partitioning of sulphur compounds is dependent on $\mathrm{pH}$ and redox conditions, but the amount present in both the biomass and the growth medium may affect the optimum solids concentration for harvesting and digestion. The greatest source of available sulphur at feedstock concentrations of $10 \%$ or less is likely to be from the culture medium in which the biomass is suspended, while the sulphur within the biomass is in its reduced state and requires oxidation before sulphate reduction can occur. Based purely on the Buswell equation, however, the maximum possible $\mathrm{H}_{2} \mathrm{~S}$ concentrations would range from $3400 \mathrm{ppmv}$ for the laboratory-grown Scenedesmus sp. to $44600 \mathrm{ppmv}$ for Dunaliella sp., with values above $10000 \mathrm{ppmv}$ for all of the marine species. All of these are problematic in downstream biogas use, even after scaling for the degree of degradation achieved.

Salinity is a further issue for marine species, due to toxicity from light metal cations and particularly sodium: in this case, however, the solids concentration of the micro-algal feedstock and the reactor retention time are likely to have relatively little effect as the operating concentration of these ions is likely to be close to that in the growth medium. Excluding outliers, such as the value of $60 \mathrm{~g} \mathrm{Na} \mathrm{L}^{-1}$ based on interpolation between 20.8 and $120 \mathrm{~g} \mathrm{Na} \mathrm{L}^{-1}$ under batch conditions [53], reported tolerances for sodium in non-acclimated mesophilic consortia are generally $<12.0 \mathrm{~g} \mathrm{Na}^{+} \mathrm{L}^{-1}$ [25], which is considerably below the average concentration found in seawater. The main ions in sea water $\left(\mathrm{Na}^{+}, \mathrm{K}^{+}, \mathrm{Mg}^{+}\right.$and $\left.\mathrm{Ca}^{++}\right)$ are required in moderate concentrations for microbial growth and can have both an inhibitory and stimulating effect [25], but at sea water salinity adaption may be required before fullscale anaerobic digestion of marine material is considered [54, 55]. Thus it is likely that simple acclimatisation protocols will have to be developed to generate inoculum for largescale commercial operation, in order to avoid the need for expensive washing procedures.

\section{Conclusions}


The work confirmed other studies that have shown wide variability between different microalgal species with respect to their potential as substrates for methane production through anaerobic digestion. Although biochemical methane potentials were consistent with median values reported in the literature, few generalisations could be made: there was no evidence that marine species were better candidates compared to freshwater species or vice versa; the percentage of volatile carbon convertible to biogas differed considerably, as did rates of degradation under anaerobic conditions; and similar species grown in different conditions (laboratory or large-scale cultivation) showed little uniformity. The results clearly indicate that a much deeper knowledge of the factors affecting the degradability of micro-algal biomass is desirable for understanding the heterogeneity of this material as a potential renewable energy source via this route. The current work goes some way towards establishing a potential protocol for the screening of algal biomass taking into account not only its inherent anaerobic biodegradability but also its likely productivity as calculated from the biomass yield, under standard conditions in each case.

\section{Acknowledgements}

Thanks are due to the UK Engineering and Physical Sciences Research Council and the EU FP7 ALL-GAS (268208) and ECOFUEL (246772) projects for supporting this research, and to Dr John Gittins from the National Oceanography Centre in Southampton for providing marine species and Jose Louis Mendoza Martin and the team in Almeria for large-scale micro-algal samples.

\section{References}

[1] Y. Chisti, Biodiesel from microalgae, Biotechnology Advances, 25 (2007) 294-306.

[2] A. Melis, Green alga hydrogen production: progress, challenges and prospects, International Journal of Hydrogen Energy, 27 (2002) 1217-1228.

[3] K. Skjånes, P. Lindblad, J. Muller, BioCO2 - A multidisciplinary, biological approach using solar energy to capture $\mathrm{CO} 2$ while producing $\mathrm{H} 2$ and high value products, Biomolecular Engineering, 24 (2007) 405-413.

[4] A.-M. Lakaniemi, C.J. Hulatt, D.N. Thomas, O.H. Tuovinen, J.A. Puhakka, Biogenic hydrogen and methane production from Chlorella vulgaris and Dunaliella tertiolecta biomass, Biotechnology for Biofuels, 4 (2011).

[5] J.R. Benemann, Opportunities and challenges in algae biofuels production, in: Algae World, Singapore, 2008. Available

http://www.greenchoices.cornell.edu/downloads/energy/biofuels/Algae_Biofuels_Production. pdf, last accessed August 2015.

[6] C.G. Golueke, W.J. Oswald, H.B. Gotaas, Anaerobic digestion of algae, Appl Microbiol, 5 (1957) 47-55.

[7] E.G. Foree, P.L. McCarty, Anaerobic decomposition of algae, Environmental Science \& Technology, 4 (1970) 842-849.

[8] C.M. Asinari Di San Marzano, A. Legros, H.P. Naveau, E.J. Nyns, Biomethanation of the marine algae Tetraselmis, International Journal of Solar Energy, 1 (1983) 263-272.

[9] E.P. Sanchez Hernandez, L.T. Cordoba, Anaerobic digestion of Chlorella vulgaris for energy production, Resources Conservation and Recycling, 9 (1993) 127-132.

[10] A. Vergara-Fernández, G. Vargas, N. Alarcón, A. Velasco, Evaluation of marine algae as a source of biogas in a two-stage anaerobic reactor system, Biomass and Bioenergy, 32 (2008) 338-344. 
[11] L. De Schamphelaire, W. Verstraete, Revival of the biological sunlight-to-biogas energy conversion system, Biotechnology and Bioengineering, 103 (2009) 296-304.

[12] M. Ras, L. Lardon, S. Bruno, N. Bernet, J.-P. Steyer, Experimental study on a coupled process of production and anaerobic digestion of Chlorella vulgaris, Bioresource Technology, 102 (2011) 200-206.

[13] C. Zamalloa, N. Boon, W. Verstraete, Anaerobic digestibility of Scenedesmus obliquus and Phaeodactylum tricornutum under mesophilic and thermophilic conditions, Applied Energy, 92 (2012) 733-738.

[14] B. Sialve, N. Bernet, O. Bernard, Anaerobic digestion of microalgae as a necessary step to make microalgal biodiesel sustainable, Biotechnology Advances, 27 (2009) 409-416.

[15] S. Heaven, J. Milledge, Y. Zhang, Comments on 'Anaerobic digestion of microalgae as a necessary step to make microalgal biodiesel sustainable', Biotechnology Advances, 29 (2011) 164-167.

[16] B. Zhao, J. Ma, Q. Zhao, L. Laurens, E. Jarvis, S. Chen, C. Frear, Efficient anaerobic digestion of whole microalgae and lipid-extracted microalgae residues for methane energy production, Bioresource Technology, 161 (2014) 423-430.

[17] M.P. Caporgno, R. Trobajo, N. Caiola, C. Ibáñez, A. Fabregat, C. Bengoa, Biogas production from sewage sludge and microalgae co-digestion under mesophilic and thermophilic conditions, Renewable Energy, 75 (2015) 374-380.

[18] H.-W. Yen, D.E. Brune, Anaerobic co-digestion of algal sludge and waste paper to produce methane, Bioresource Technology, 98 (2007) 130-134.

[19] S. Park, Y. Li, Evaluation of methane production and macronutrient degradation in the anaerobic co-digestion of algae biomass residue and lipid waste, Bioresource Technology, 111 (2012) 42-48.

[20] P.J. McGinn, K.E. Dickinson, K.C. Park, C.G. Whitney, S.P. MacQuarrie, F.J. Black, J.C. Frigon, S.R. Guiot, S.J.B. O'Leary, Assessment of the bioenergy and bioremediation potentials of the microalga Scenedesmus sp. AMDD cultivated in municipal wastewater effluent in batch and continuous mode, Algal Research, 1 (2012) 155-165.

[21] Y. Su, A. Mennerich, B. Urban, Municipal wastewater treatment and biomass accumulation with a wastewater-born and settleable algal-bacterial culture, Water Research, 45 (2011) 3351-3358.

[22] J. Sheeman, T. Dunahay, J. Benemann, P. Roessler, A Look Back at the US Department of Energy's Aquatic Species, Program - Biodiesel from Algae. US Department of Energy's Office of Fuels Development. National Renewable Energy Laboratory, 328p, (1998).

[23] C. Zamalloa, E. Vulsteke, J. Albrecht, W. Verstraete, The techno-economic potential of renewable energy through the anaerobic digestion of microalgae, Bioresource Technology, 102 (2011) 1149-1158.

[24] P. Collet, A. Hélias, L. Lardon, M. Ras, R.-A. Goy, J.-P. Steyer, Life-cycle assessment of microalgae culture coupled to biogas production, Bioresource Technology, 102 (2011) 207-214.

[25] Y. Chen, J.J. Cheng, K.S. Creamer, Inhibition of anaerobic digestion process: A review, Bioresource Technology, 99 (2008) 4044-4064.

[26] A.J. Ward, D.M. Lewis, F.B. Green, Anaerobic digestion of algae biomass: A review, Algal Research, 5 (2014) 204-214.

[27] C. González-Fernández, B. Sialve, N. Bernet, J.-P. Steyer, Impact of microalgae characteristics on their conversion to biofuel. Part II: Focus on biomethane production, Biofuels, Bioproducts and Biorefining, 6 (2012) 205-218.

[28] F. Passos, E. Uggetti, H. Carrère, I. Ferrer, Pretreatment of microalgae to improve biogas production: A review, Bioresource Technology, 172 (2014) 403-412. 
[29] Y. Chisti, Biodiesel from microalgae beats bioethanol, Trends in Biotechnology, 26 (2008) 126-131.

[30] K.C. Tran, J.L. Mendoza Martin, S. Heaven, C.J. Banks, F.G. Acien Fernandez, E. Molina Grima, Cultivation and anaerobic digestion of Scenedesmus spp. grown in a pilotscale open raceway Algal Research, 5 (2014) 95-102.

[31] APHA, Standard Methods for the Examination of Water \& Wastewater, 21 ed., American Public Health Organisation, 2005.

[32] M. Walker, C.J. Banks, S. Heaven, J. Frederickson, Development and evaluation of a method for testing the residual biogas potential of digestates. OFW004-005. Waste and Resources Action Programme, 2010. Available online at

http://www2.wrap.org.uk/downloads/Residual_Biogas_Potential_Final.5a538181.11103.pdf, last accessed July 2015.

[33] M. Walker, Y. Zhang, S. Heaven, C. Banks, Potential errors in the quantitative evaluation of biogas production in anaerobic digestion processes, Bioresource Technology, 100 (2009) 6339-6346.

[34] G.E. Symons, A.M. Buswell, The Methane Fermentation of Carbohydrates, Journal of the American Chemical Society, 55 (1933) 2028-2036.

[35] IFRF, Online Combustion Handbook (Method from Combustion File 24), in, International Flame Research Foundation, 2014, pp. 1607-9116.

[36] M.S. Rao, S.P. Singh, A.K. Singh, M.S. Sodha, Bioenergy conversion studies of the organic fraction of MSW: assessment of ultimate bioenergy production potential of municipal garbage, Applied Energy, 66 (2000) 75-87.

[37] S. Buxy, R. Diltz, P. Pullammanappallil, Biogasification of Marine Algae

Nannochloropsis Oculata, in: Materials Challenges in Alternative and Renewable Energy II, John Wiley \& Sons, Inc., 2012, pp. 59-67.

[38] P. Bohutskyi, M.J. Betenbaugh, E.J. Bouwer, The effects of alternative pretreatment strategies on anaerobic digestion and methane production from different algal strains, Bioresource Technology, 155 (2014) 366-372.

[39] N.O. Santos, S.M. Oliveira, L.C. Alves, M.C. Cammarota, Methane production from marine microalgae Isochrysis galbana, Bioresource Technology, 157 (2014) 60-67.

[40] A. Mottet, F. Habouzit, J.P. Steyer, Anaerobic digestion of marine microalgae in different salinity levels, Bioresource Technology, 158 (2014) 300-306.

[41] C.J. Zhu, Y.K. Lee, Determination of biomass dry weight of marine microalgae, Journal of Applied Phycology, 9 (1997) 189-194.

[42] J.H. Mussgnug, V. Klassen, A. Schlüter, O. Kruse, Microalgae as substrates for fermentative biogas production in a combined biorefinery concept, Journal of Biotechnology, 150 (2010) 51-56.

[43] J.-C. Frigon, F. Matteau-Lebrun, R. Hamani Abdou, P.J. McGinn, S.J.B. O’Leary, S.R. Guiot, Screening microalgae strains for their productivity in methane following anaerobic digestion, Applied Energy, 108 (2013) 100-107.

[44] A.-M. Lakaniemi, O.H. Tuovinen, J.A. Puhakka, Anaerobic conversion of microalgal biomass to sustainable energy carriers - A review, Bioresource Technology, 135 (2013) 222231.

[45] T.M. Cole, S.A. Wells, CE-QUAL-W2: a two-dimensional, laterally averaged, hydrodynamic and water quality model, in: US Army Corps of Engineers, Washington DC, 2008.

[46] I. Angelidaki, M. Alves, D. Bolzonella, L. Borzacconi, J.L. Campos, A.J. Guwy, S. Kalyuzhnyi, P. Jenicek, J.B. van Lier, Defining the biomethane potential (BMP) of solid organic wastes and energy crops: a proposed protocol for batch assays, Water Science and Technology, 59 (2009) 927-934. 
[47] K. Roberts, Crystalline Glycoprotein Cell Walls of Algae: Their Stucture, Composition and Assembly, Philosophical Transactions of the Royal Society of London. Series B, Biological Sciences, 268 (1974) 129-146.

[48] H. Gerken, B. Donohoe, E. Knoshaug, Enzymatic cell wall degradation of Chlorella vulgaris and other microalgae for biofuels production, Planta, 237 (2013) 239-253.

[49] K. Okuda, Structure and phylogeny of cell coverings. Journal of Plant Research, 115(4) (2002) 283-288.

[50] C.J. Banks, S. Heaven, L.E.S. Corona, F. Rogalla, Energy production from integration of high rate anaerobic and algal wastewater treatment: the EU FP7 All-Gas project, in: 9th IWA Specialist Group on Waste Stabilisation Ponds, Adelaide, 2011.

[51] R. Samson, A. Leduy, Influence of mechanical and thermochemical pretreatments on anaerobic digestion of Spirulina maxima algal biomass, Biotechnology Letters, 5 (1983) 671676.

[52] H. Lindorfer, D. Ramhold, B. Frauz, Nutrient and trace element supply in anaerobic digestion plants and effect of trace element application, Water Science and Technology, 66 (2012) 1923-1929.

[53] E. Aspe, M.C. Marti, M. Roeckel, Anaerobic treatment of fishery wastewater using a marine sediment inoculum, Water Research, 31 (1997) 2147-2160.

[54] G. Feijoo, M. Soto, R. Méndez, J.M. Lema, Sodium inhibition in the anaerobic digestion process: Antagonism and adaptation phenomena, Enzyme and Microbial Technology, 17 (1995) 180-188.

[55] L.A. de Baere, M. Devocht, P. Van Assche, W. Verstraete, Influence of high $\mathrm{NaCl}$ and $\mathrm{NH} 4 \mathrm{Cl}$ salt levels on methanogenic associations, Water Research, 18 (1984) 543-548. 